\title{
Is there any evidence for a protective effect of antithrombotic medication on cognitive function in men at risk of cardiovascular disease? Some preliminary findings
}

\author{
M Richards, T W Meade, Sir Stanley Peart, P J Brennan, A H Mann
}

\begin{abstract}
To explore whether antithrombotic medication may protect against cognitive decline, tests of verbal memory, attention, abstract reasoning, verbal fluency, and mental flexibility were administered to $\mathbf{4 0 5}$ men at risk of cardiovascular disease. These subjects were a subgroup of those who had been participating in a randomised double blind factorial trial of low dose aspirin (75 mg daily) and low intensity oral anticoagulation with warfarin (international normalised ratio of 1.5) at 35 general practices across the United Kingdom for at least five years, were at least 55 years old at trial entry, and had been randomly allocated to one of four groups: active warfarin and active aspirin, active warfarin and placebo aspirin, placebo warfarin and active aspirin, and double placebo. Verbal fluency and mental flexibility were significantly better in subjects taking antithrombotic medication than in subjects taking placebo. Aspirin may have contributed more than warfarin to any beneficial effect. These results provide tentative evidence that antithrombotic medication may protect cognitive function in men at risk of cardiovascular disease.
\end{abstract}

$(\mathfrak{F}$ Neurol Neurosurg Psychiatry 1997;62:269-272)

Keywords: cognitive; aspirin; warfarin; cardiovascular; antithrombotic

A growing body of evidence suggests an association between cardiovascular risk factors and cognitive impairment during aging. These risk factors include hypertension, diabetes, hypercholesterolaemia, and cardiac disease such as atrial fibrillation and angina, all of which may promote neuropathological changes resulting from microthromboses in cerebral blood vessels. Antithrombotic medication may therefore protect cognitive function. In a randomised placebo controlled trial, Meyer et al ${ }^{\prime}$ found that aspirin improved cognitive function in patients with multi-infarct dementia. Little is known, however, about the effect of antithrombotic medication on cognitive function in those without frank dementia. Population based studies have either reported no association ${ }^{2}$ or a modest trend towards protection of cognitive function ${ }^{3}$ from medication (non-steroidal anti-inflammatory drugs and aspirin). However, these authors relied on recall of use of medication and, in both studies, employed a single, global measure of current cognitive status.

In the present study we measured cognitive function in patients already enrolled in a double blind placebo controlled factorial trial of low dose aspirin and low intensity oral anticoagulation with warfarin for their effect on the prevention of coronary and cerebral thrombosis. The purpose was to assess whether those who were on active treatment showed differences in cognitive performance compared with those who were receiving placebo. Because this cognitive study was conducted after the trial was already in progress, no baseline cognitive test data are available for comparison. Nevertheless, we were able to take advantage of the randomised design and detailed monitoring during a five year interval. The content of our neuropsychological test battery was based on studies that reported an association between cardiovascular risk factors and impairments in memory, attention, and abstract reasoning. ${ }^{4-6}$

\section{Methods}

MEDICAL RESEARCH COUNCIL THROMBOSIS PREVENTION TRIAL (TPT)

This trial is taking place within the Medical Research Council's general practice research framework and involves 101 collaborating general practices. A chart review of all men aged between 45 and 69 in these practices was carried out by the trial nurse. Those who were not excluded on grounds of contraindications to a TPT drug (aspirin and warfarin) or likely poor compliance, were invited to attend for screening to assess cardiovascular risk status. Screening procedures are described in detail elsewhere ${ }^{78}$ and identified those in the top quintile of risk for myocardial infarction or coronary death, using a score based on family and smoking history, blood pressure, body mass index, blood cholesterol, plasma fibrinogen, and plasma factor VII activity. Those at high risk were invited to enter the trial, in 
which they were randomised to active warfarin and active aspirin (WA), active warfarin and placebo aspirin (W), active aspirin and placebo warfarin (A), or double placebo treatment $(\mathbf{P})$.

Participants are examined at entry and, once stabilised on treatment, at three monthly intervals by the trial nurse and at annual examinations by the general practitioner. Treatment with warfarin is initiated at a dose of $2.5 \mathrm{mg}$ daily and increased by 0.5 or $1.0 \mathrm{mg}$ steps until the intended international normalised ratio (INR) of about 1.5 has been reached. On average, this stabilisation process takes about four months. Dose changes are made equally often for those receiving placebo warfarin treatment with identical tablets. The dose of aspirin is $75 \mathrm{mg}$ daily in a controlled release formulation, also with identical placebo tablets.

\section{Subjects}

Subjects eligible for this cognitive substudy were (1) aged at least 55 at entry and (2) had been participating in the trial for five years or more. Older trial entrants were thought to be most likely to show cognitive changes, and those participating in the trial for five years had received antithrombotic treatment for long enough for any effect of treatment on cognitive function to be evident. Of all 101 practices, 35 included men meeting the above criterion of treatment for at least five years. A difference of five seconds in part $A$ of the trailmaking test (which has a large variance) is of potential functional significance for subjects in the age group of those in the present study. ${ }^{9} \mathrm{~A}$ sample of 350 subjects was estimated to be necessary to detect this effect with a power of $90 \%$ at a $5 \%$ level of significance. Of 1001 subjects originally meeting the above criteria, 493 had either already completed the TPT study or were no longer participating. Morbidity data, including causes of adverse events and death, will be available at the end of the TPT study. Of the remaining 508 eligible subjects, 60 were in practices where training for the neuropsychological tests could not be arranged and 24 subjects declined to be tested (nine in the $\mathrm{P}$ group, six in the $\mathrm{A}$ group, six in

Table 1 Baseline risk factor and background demographic data for the four treatment groups

\begin{tabular}{|c|c|c|c|c|}
\hline \multirow[b]{2}{*}{ Variable } & \multicolumn{4}{|l|}{ Groups } \\
\hline & $W A$ & $W$ & $A$ & $P$ \\
\hline No & 108 & 107 & 97 & 93 \\
\hline Age at testing (y) & $66 \cdot 7(3 \cdot 8)$ & $66 \cdot 9(4 \cdot 1)$ & $66 \cdot 0(3 \cdot 5)$ & $66 \cdot 1(4 \cdot 0)$ \\
\hline Education (y) & $10 \cdot 0(2 \cdot 2)$ & $10 \cdot 0(2 \cdot 2)$ & $10 \cdot 7(2 \cdot 3)$ & $10 \cdot 1(1 \cdot 8)$ \\
\hline Time in trial $(y)$ & $5.5(1.0)$ & $5.4(0.9)$ & $5.5(0.9)$ & $5 \cdot 6(1 \cdot 2)$ \\
\hline Body mass index $\left(w t / h t^{2}\right)$ & $38 \cdot 1(10 \cdot 3)$ & $38 \cdot 4(10 \cdot 0)$ & $37 \cdot 8(12 \cdot 0)$ & $40 \cdot 3(13.9)$ \\
\hline $\begin{array}{l}\text { Systolic blood pressure } \\
\text { (mm Hg) }\end{array}$ & $139 \cdot 5(17 \cdot 6)$ & $144 \cdot 2(18 \cdot 2)$ & $142 \cdot 1(19 \cdot 5)$ & $142 \cdot 7(18 \cdot 5)$ \\
\hline $\begin{array}{l}\text { Diastolic blood pressure } \\
(\mathrm{mm} \mathrm{Hg})\end{array}$ & $81 \cdot 1(10 \cdot 0)$ & $82 \cdot 8(9 \cdot 4)$ & $82 \cdot 2(9 \cdot 7)$ & $83.6(11 \cdot 6)$ \\
\hline Cigarettes/day & $4.6(8 \cdot 5)$ & $5 \cdot 6(8 \cdot 2)$ & $6 \cdot 7(9 \cdot 6)$ & $4.5(8 \cdot 2)$ \\
\hline Factor VII (\% standard) & $104 \cdot 6(26 \cdot 6)$ & $104 \cdot 2(27 \cdot 3)$ & $108 \cdot 7(28.50$ & $114 \cdot 4(28 \cdot 2)$ \\
\hline INR & $1 \cdot 0(0 \cdot 1)$ & $1 \cdot 0(0 \cdot 1)$ & $1 \cdot 0(0 \cdot 1)$ & $1 \cdot 0(0 \cdot 1)$ \\
\hline Plasma cholesterol $(\mathrm{mmol} / \mathrm{l})$ & $6 \cdot 3(1 \cdot 3)$ & $6 \cdot 1(1 \cdot 2)$ & $6.0(1 \cdot 8)$ & $6.3(1.6)$ \\
\hline Plasma fibrinogen $(\mathrm{g} / \mathrm{l})$ & $296 \cdot 6(82 \cdot 3)$ & $306.5(93 \cdot 6)$ & $287 \cdot 4(104 \cdot 1)$ & $290 \cdot 4(83 \cdot 3)$ \\
\hline $\begin{array}{l}\text { Family history of heart } \\
\text { disease }(\%)\end{array}$ & & & $18 \cdot 6$ & $20 \cdot 4$ \\
\hline $\begin{array}{l}\text { disease (\%) } \\
\text { ECG ischaemia (\%) }\end{array}$ & $\begin{array}{r}13 \cdot 7 \\
2 \cdot 8\end{array}$ & $\begin{array}{r}140 \\
4.7\end{array}$ & $\begin{array}{r}10 \cdot 2 \\
5 \cdot 2\end{array}$ & $3 \cdot 2$ \\
\hline
\end{tabular}

Values are means (SD). INR = international normalised ratio. See text for groups. the W group, and two in the WA group). Thus 424 subjects underwent cognitive testing. All subjects gave signed informed consent.

\section{COGNITIVE MEASURES}

The following tests were administered at the relevant follow up assessment but not at trial entry. (1) Logical memory subtest of the Wechsler memory scale ${ }^{10}$ (immediate and delayed); a measure of memory decline was obtained by subtracting the delayed from the immediate score and this measure was used in the present analyses. (2) Digit span subtest of the revised Wechsler adult intelligence scale (WAIS-R ${ }^{11}$ ). (3) A cancellation task ${ }^{12}$; subjects were required to cross out, as quickly as possible, letter triads (TMX) from an array of similar triads. The lower the score, the better the performance. (4) Trailmaking test ${ }^{13}$ (parts A and $B$ ). A measure of mental flexibility was gained by subtracting part $A$ from part $\mathrm{B}^{14}$ and this measure was used in the present analyses. The lower the value, the better the performance. (5) The similarities subtest of the WAIS-R was used to assess abstract reasoning. (6) Verbal fluency was assessed by (a) production of animal names ${ }^{15}$ and $(b)$ production of words beginning with the letter $F{ }^{16}$ One minute was allowed for each.

Five regional nurse coordinators underwent standardised training by the first author to administer the neuropsychological tests. They then instructed clinic nurses, who administered the tests blind to medication status. This training required observation and practice and emphasised strict adherence to formal written protocols for each test.

\section{Results}

\section{BASELINE CHARACTERISTICS}

Table 1 shows the baseline characteristics for subjects in the four treatment groups who underwent cognitive testing.

There were no significant differences in age, education, body mass index, systolic or diastolic blood pressure, number of cigarettes smoked per day, plasma cholesterol, plasma fibrinogen, ECG, ischaemia, or family history of heart disease. Nor was there any difference between the groups in duration in the trial at the time of cognitive testing. Subjects in the placebo group had a slightly higher factor VII activity level at baseline compared with subjects in the active treatment groups $(P=$ $0 \cdot 04)$. There were no significant differences in these baseline characteristics between subjects who underwent cognitive testing and those from the original pool of 1001 who would have been eligible for cognitive testing.

\section{COGNITIVE FUNCTION AND ANTITHROMBOTIC} MEDICATION

Subjects were first grouped into those receiving placebo only and those on any active medication (WA, A, or W). Table 2 shows the cognitive scores for these two groups.

Multivariate analysis of variance (MANOVA) was employed, using Hotelling's $\mathrm{T}^{2}$ statistic to compare the multiple cognitive 
Table 2 Cognitive scores for subjects taking active treatment $v$ placebo only

\begin{tabular}{lll}
\hline Variable & $\begin{array}{l}\text { Any active } \\
\text { treatment }\end{array}$ & Placebo \\
\hline No & 312 & 93 \\
Logical memory decline (s) & $2 \cdot 2(1 \cdot 5)$ & $2 \cdot 4(1 \cdot 5)$ \\
Digit span & $11 \cdot 4(2 \cdot 2)$ & $11 \cdot 6(2 \cdot 5)$ \\
Cancellation (s) & $61.9(17 \cdot 9)$ & $62 \cdot 3(17 \cdot 8)$ \\
Similarities & $17 \cdot 3(4 \cdot 5)$ & $17 \cdot 6(4 \cdot 2)$ \\
Animal naming & $20 \cdot 2(5 \cdot 4)$ & $18 \cdot 9(4 \cdot 9)^{\star}$ \\
Letter naming (F) & $12 \cdot 6(4 \cdot 8)$ & $12 \cdot 0(4 \cdot 8)$ \\
Trails B-A (s) & $50 \cdot 2(31 \cdot 0)$ & $59 \cdot 7(37 \cdot 4)^{\star}$ \\
\hline Values are means (SD). & & \\
${ }^{*} \mathrm{p}<0 \cdot 05$. & &
\end{tabular}

measures across these two groups. Nineteen subjects had missing values for at least one cognitive measure, including four subjects who completed the trailmaking $B$ test more rapidly than trailmaking $A$, indicating probable test administration error. As MANOVA rejects cases with missing data for any variable, the results for these subjects were omitted from the analysis, leaving 405 men in the study. MANOVA disclosed a significant medication effect for the cognitive scores (Hotelling's $\quad T^{2}=0.04, \quad P=0.013$ ). Corresponding univariate $\mathrm{F}$ tests disclosed poorer performance for subjects taking placebo only for animal naming $(F=4.51, \mathrm{P}$ $=0.034)$ and trailmaking part B-A $(F=$ $6 \cdot 06, P=0 \cdot 014$ ).

\section{EFFECT OF SPECIFIC REGIMES}

MANOVA was then used to compare cognitive function in the four separate treatment groups. Univariate $F$ tests showed a significant group effect for WAIS-R Similarities $(F=$ $2.64, P=0.049$ ), with poorest performance in the W group. However, as Hotelling's $\mathrm{T}^{2}$ test was not significant, the possibility that this was a type I error cannot be ruled out.

These analyses suggested the possibility of better cognitive performance by patients taking aspirin than in patients taking warfarin. Table 3 therefore shows the results for all those taking aspirin (WA and A) compared with those not taking aspirin (W and $P$ ) and for all those taking warfarin (WA and W) compared with those not taking warfarin (A and P) - that is, a factorial design for separate treatment effects.

In the comparison according to warfarin allocation, several test scores were, if anything, poorer in those on active warfarin than with those who were not, significantly so for similarities $(F=5.49, \mathrm{P}=0.02)$, although, once again, Hotelling's $\mathrm{T}^{2}$ test was not significant.

Table 3 Cognitive scores for subjects taking or not taking aspirin and for subjects taking or not taking warfarin

\begin{tabular}{|c|c|c|c|c|}
\hline & \multicolumn{2}{|l|}{ Taking aspirin } & \multicolumn{2}{|l|}{ Taking warfarin } \\
\hline & $Y e s(W A+A)$ & $N o(W+P)$ & Yes $(W A+W)$ & No $(A+P)$ \\
\hline $\begin{array}{l}\text { LM (decay) } \\
\text { Digit span } \\
\text { Cancellation (s) } \\
\text { Similarities } \\
\text { Animal naming } \\
\text { Letter naming (F) } \\
\text { Trails B-A (s) }\end{array}$ & $\begin{array}{l}2 \cdot 2(1 \cdot 5) \\
11 \cdot 5(2 \cdot 3) \\
61 \cdot 3(17 \cdot 7) \\
17 \cdot 7(4 \cdot 2) \\
20 \cdot 4(5 \cdot 4) \\
12 \cdot 6(4 \cdot 8) \\
49 \cdot 1(29 \cdot 9)\end{array}$ & $\begin{aligned} 2 \cdot 2(1 \cdot 5) \\
11 \cdot 5(2 \cdot 4) \\
62 \cdot 7(18 \cdot 0) \\
17 \cdot 0(4 \cdot 7) \\
19 \cdot 4(5 \cdot 1) \\
12 \cdot 3(4 \cdot 7) \\
55 \cdot 8(35 \cdot 3)\end{aligned}$ & $\begin{array}{l}2 \cdot 1(1 \cdot 5) \\
11 \cdot 4(2 \cdot 2) \\
62 \cdot 0(19 \cdot 4) \\
16 \cdot 9(4 \cdot 7) \\
20 \cdot 0(5 \cdot 3) \\
12 \cdot 4(4 \cdot 7) \\
51 \cdot 8(31 \cdot 8)\end{array}$ & $\begin{array}{l}2 \cdot 4(1 \cdot 4) \\
11 \cdot 6(2 \cdot 4) \\
61 \cdot 9(16 \cdot 0) \\
17 \cdot 9(4 \cdot 0) \\
19 \cdot 8(5 \cdot 3) \\
12 \cdot 5(4 \cdot 9) \\
53 \cdot 1(34 \cdot 0)\end{array}$ \\
\hline
\end{tabular}

Values are means (SD).

$\mathrm{LM}=$ Logical memory. See text for groups.
EFFECT OF RISK FACTOR VARIABLES

Correlations were calculated between time to complete the trailmaking B-A test and the cardiovascular risk factor values. Values at screening (see methods), as close as possible to the time of cognitive testing and the mean across the repeated assessments were used. All correlation coefficients fell within a range of $-0 \cdot 1$ to $0 \cdot 1$. Thus there were virtually no associations between the risk factors and the trailmaking B-A score. A similar pattern was observed when the $\mathrm{P}$ group and the combined treatment groups were analysed separately. There was no significant difference in the trailmaking B-A score between subjects with and without a family history of cardiovascular disease.

\section{Discussion}

As part of a double blind factorial trial of the effect of antithrombitic medication on the prevention of coronary heart disease we found that 405 of the older subjects who had been taking low dose or low intensity antithrombotic medication with warfarin, or aspirin, or both for about five years showed better cognitive performance than subjects given only placebo. We found this trend in most cognitive scores. Any effect was probably mainly due to aspirin. More specifically, scores for animal naming (a test of verbal fluency) and part B-A of the trailmaking test were significantly better in subjects taking active medication. Both of these tests are effortful, require mental control and flexibiliy, and are thought to be under frontal control. The trailmaking tests require motor speed and visual scanning although these elements were controlled in part by subtracting part A from part B and were not, in any case, sensitive to medication in the cancellation test.

Caution is necessary in interpreting the results of this or any other study that consists of a subgroup analysis within a trial that was designed for another purpose. Firstly, we did not measure cognitive function at baseline. The possibility that treatment might influence cognitive function was only raised after the trial had started. We have to assume that the groups were similar in cognitive function at baseline, which seems likely. They were well matched in other respects and there was no discernable difference between those cognitively tested and those potentially available but not tested. Secondly, cognitive tests were administered by nurses with no previous experience in neuropsychological testing. Nevertheless, they received structured training, were guided by written test protocols, and were in any case blind to the medication status of each patient. Thirdly, the effect of antithrombotic medication on cognitive function, although significant, was generally slight although we would argue, in line with Gorkin et al, ${ }^{9}$ that the effect for Part B-A of the trailmaking test (a difference of 9.5 seconds between placebo and active treatment groups) is of functional significance.

Whereas it should be born in mind that 
variance for the cardiovascular risk factors was restricted in this sample, the striking absence of correlations between any of the risk factors and time to complete part B-A of the trailmaking test was unexpected and brings into question the starting hypothesis of a vascular explanation for the wide range of scores found. Aspirin in the thrombosis prevention trial is low dose, $75 \mathrm{mg}$ daily, and in a controlled release formulation designed for a prehepatic effect by reducing thromboxane in the platelets themselves while sparing prostacyclin production in the systemic vasculature after the liver metabolism of aspirin to salicylate, which is only weakly active.$^{17}$ If aspirin does preserve cognitive function, it may perhaps do so through some pathway other than its effect on platelets and thrombogenesis, in which case a higher dose than the $75 \mathrm{mg}$ used in the thrombosis prevention trial and in a formulation subject to less extensive first pass metabolism in the liver might result in a larger benefit. Further investigations of the association between antithrombotic medication and cognitive function are warranted.

The salary of MR is currently provided by the Alzheimer's Disease Society. We wish to acknowledge the help of the MRC general practice research framework doctors and nurses. Specific thanks are due to Mrs Pam Allen, Mrs Leslie Hand, Marshall for coordination of nurse training for this study.

1 Meyer JS, Rogers RL, McClintic K, Mortel KF, Lofti J. Randomized clinical trial of daily aspirin therapy in multi-infarct dementia: a pilot study. $\mathscr{f} \mathrm{Am}$ Geriatr Soc 1989;37:549-55

2 May FE, Moore MT, Stewart RB, Hale WE. Lack of association of non-steroidal anti-inflammatory drug use and cognitive decline in the elderly. Gerontology 1992;38: 275-9.

3 Sturmer T, Glynn RJ, Field TS, Taylor JO, Hennekens $\mathrm{CH}$. Aspirin use and cognitive function in the elderly. Am 7 Epidemiol 1996;143:683-91.

4 Waldstein SR, Manuck SB, Ryan CM, Muldoon MF Neuropsychological correlates of hypertension: review and methodologic considerations. Psychol Bull 1991;110: 451-68.

5 Bornstein RA, Kelly MP. Risk factors for stroke and neuropsychological performance. In: Bornstein RA Brown GG, eds. Neurobehavioral aspects of cerebrovascular disease. New York: Oxford University Press, 1991: 182-201.

6 Desmond DW, Tatemichi TK, Paik M, Stern Y. Risk factors for cerebrovascular disease as correlates of cognitive function in a stroke-free cohort. Arch Neurol 1993;50: 162-6.

7 Meade TW, Wilkes HC, Brennan PJ, Kelleher C, Browne W. Randomised controlled trial of low dose warfarin in the primary prevention of IHD in men at high risk: the primary prevention of IHD in men at high

8 Meade TW, Roderick PJ, Brennan PJ, Wilkes HC, Kelleher CC. Extracranial bleeding and other symptoms due to low dose aspirin and low intensity oral anticoagulation. Thromb Haemost 1992;68:1-6.

9 Gorkin L, Norvell NK, Rosen RC, Charles E, Shumaker $\mathrm{SA}, \mathrm{McIntyre} \mathrm{KM}$, et al. Assessment of quality of life as observed from the baseline data of the studies of left ventricular dysfunction (SOLVD) trial quality-of-life substudy. Am F Cardiol 1993;71:1069-73.

10 Wechsler D. A standardized memory scale for clinical use. $f$ Psychol 1945;19:87-95.

11 Wechsler D. Wechsler adult intelligence scale-revised. New York: Psychological Corporation, 1981.

12 Reitan RM, Wolfson D. The Halstead-Reitan neuropsychological test battery: theory and clinical interpretation. Tuscon, AZ: Neuropsychology Press, 1985.

13 Taylor AE, Saint-Cyr JA, Lang AE Frontal lobe Taylor AE, Saint-Cyr JA, Lang AE. Frontal lobe 845-83.

14 Sano M, Rosen W, Mayeux R. Attention deficits in Alzheimer's disease. Washington, DC: American Psychiatric Association, 1984.

15 Goodglass H, Kaplan D. The assessment of aphasia and related disorders. 2nd ed. Philadelphia, PA: Lea and Febinger, 1983

16 Benton AL, Hamsher K. Multilingual aphasia examination. Iowa City: University of Iowa Hospitals, 1978.

17 Clarke RJ, Mayo G, Price P, Fitzgerald GA. Suppression of thromboxane A2 but not of prostacyclin by controlledrelease aspirin. $N$ Engl $\mathcal{F}$ Med 1991;325:1137-41. 